\title{
Importância e Papel dos Fornecedores Turísticos na Organização de Eventos
}

\author{
Mário de Mello Faro!
}

RESUMO: Trata da importância e papel dos tomecedores turisticos no planejamento, organização e realização de eventos, principalmente os de caráter técnico-cientifico. Destaca a relação evento / agência de viagem, meios de hospedagem e companhia de transporte aéreo, sendo a primeira o elemento de ligação do organizador de eventos com os demais fomecedores turísticos.

PALAVRAS-CHAVE: Turismo e eventos; tomecedores turisticos; agência de viagem; meios de hospedagem; companhia de transporte aéreo; importância e papel.

ABSTRACT: The text focuses on the importance and roll at the tourist suppliers in the planning, organization and achievement of events. It also leads to a relationship amongst the travel agents, hotels and air transport companies, which estrategically places the first as a link between event planners and others touristic suplliers.

KEY WORDS: Tourism and events; touristic suppliers; travel agent; hotel; air transport companie; importance and roll.

A evolução célere dos meios de comunicação tem permitido ao homem rápido envolvimento com todas as áreas da experiência e do conhecimento humano. Hoje, em poucos minutos, o mundo todo acolhe determinado acontecimento, festejando ou lamentando, conforme sua mensagem. Por outro lado, na medida em que o homem ascende na escalada econômica e sociocultural, torna-se necessidade permanente o intercâmbio de informações, idéias e técnicas. A reunião, em sentido lato sensu, nas suas várias modalidades, adquiriu formas muito especiais, para que a riqueza dos conhecimentos não ficasse restrita a poucos, mas fosse extensiva a grande parte da humanidade.

1. Gerente da Casa Faro Turismo e Câmbio S. A. de 1961 a 1991. Membro de várias entidades de Turismo, honrado com a medalha Johan Strauss. Atual diretor da Mello Faro Turismo e Câmbio Ltda

End. para corresp.: Av. São Luis, 165 - $1^{\circ}$ andar, cj. IA - 01046-911 - São Paulo - SP - Brasil. Fax: (011) 231-1343. 
A seguir descreve-se o papel dos componentes do "trade", na organização e execução de um evento.

\section{Agência de Viagens}

Cabe à agência de viagens o planejamento e a execução das atividades turísticas propriamente ditas, imprescindiveis ao desempenho técnico do evento, essencialmente naqueles em que o debate científico não é a única aspiração. A agência de viagens tem como competência assessorar a comissão organizadora, participando ativamente das reuniões da mesma, colaborando na planificação geral, buscando somar esforços com o organizador do evento e com a entidade promotora.

Nunca é demais repetir que a agência constitui o elemento de ligação dos mesmos, junto com a hotelaria, o transporte aéreo e de superfície, os locais de visitação turísticae demais fornecedores específicos. Sua intervenção é primígena, com maior ou menor intensidade, tanto nos eventos nacionais como nos internacionais, quer sejam receptivos quer sejam emissivos, cobrindo, fundamentalmente, os setores abaixo relacionados.

\section{Turismo}

Mediante moderno ebem-organizado departamento especifico, com pessoal conhecedor da tecnologia atual, a agência de viagens desenvolve atividades turísticas programadas, de acordo com a decisão da comissão organizadora, sendo de sua responsabilidade imediata os seguintes serviços:

- recepção: manter conjunto de pessoas uniformizadas nas principais "portas" de entrada do país, basicamente nos aeroportos de tráfego nacional e internacional, e, de preferência, identificados com o crachá do evento ou da empresa, bilíngüe ou não, que deverá estar à disposição, pelo menos, durante os dois primeiros dias para receber os participantes, mormente estrangeiros, em nome da entidade promotora ou do próprio evento. O uso de cartazes, como nomedo evento, é de grande utilidade para o convencional reconhecer os recepcionistas, propiciando, um clima de tranqüilidade e segurança;

- traslado: em seguida, os congressistas serão encaminhados para o local de estacionamento do transporte de superfície de onde, em veículos especiais, ônibus, microônibus ou carros, serão levados aos hotéis. Não é recomendável reter os ônibus para atender vários vôos que chegam em horários próximos. É cansativo e inoportuno. Prioritariamente, os ônibus deverão ser de boa categoria, com ar condicionado ou não, com número variável de assentos, compatível com as necessidades. Deverão ainda ser numerados, indicando o nome do hotel ou hotéis aos quais se destinam. Eventualmente, a condução em ônibus ou carros de serviço regular poderá ser utilizada do aeroporto para a região metropolitana da cidade, com tarifas bem acessiveis. O transporte para os hotéis obedecerá a um esquema previsto, por exemplo, região central, jardins, sul ou norte, onde há a predominância dos mesmos, evitando-se assim o dispêndio de tempo no meio do tráfego. Quando o traslado não está incluído no programa receptivo, dever-se-á, pelo menos, manter recepcionistas no aeroporto para as medidas de praxe. Recomenda-se especial atenção para o controle de bagagem despachada, tanto nos aeroportos quanto nos hotéis, a fim de prevenir perdas ou roubos - causas iniciais de má impressão e prejuizos conseqüentes. As malas, devidamente etiquetadas com o nome do proprietário, deverão ser contadas pelo guia e colocadas no rooming list, ao lado do nome do participante. É sempre de grande utilidade, aconselhar os convencionais que não abandonem suas bagagens e exerçam severo policiamento sobre essas, de modo a facilitar sua contagem e identificação. Coordenadores do transporte, munidos de instrumentos de comunicação para orientar e dirigir o fluxo, contribuirão para o sucesso da recepção e do traslado;

- programa social, atividades de acompanhantes e visitas à cidade: muitas vezes, a agência de viagens se envolve com a programação social, desde 0 ato inaugural até as atividades dos acompanhantes, sobretudo as turisticas. O levantamento dos recursos disponiveis para passeios pela cidade, visitando museus e principais pontos turísticos, deverá ser encaminhado para decisão final da comissão organizadora e conseqüente inclusão no programa oficial, custeados pela própria taxa de inscrição ao evento. Quando não inseridos, serão considerados serviços opcionais e dever-se-á cobrar dos convencionais, de acordo com as tarifas estipuladas. Os programas turísticos devem ser elaborados com a devida antecedência e, em seguida, encaminhados aos possíveis participantes, constituindo forte atrativo de adesão ao evento. Cabe também o acréscimo de atividades noturnas, como ir a restaurantes e bares em moda, espetáculos vários, visitas a bairros típicos etc. Geralmente, essas atividades são opcionais e cobra-se taxa de adesão;

- programas turisticos pré e pós-evento: as excursões com essas particularidades deverão ser organizadas antecipadamente e divulgadas entre os possíveis participantes, pois constituem forte argumento para aumentar a demanda pelo evento. As excursões poderão ter duração e destino variáveis. O Brasil vem oferecendo roteiros que contemplam o Rio de Janeiro, Iguaçu, Brasília, Salvador, Manaus e São Paulo, cidades que, com atrativos peculiares e diversos, podem ser visitadas individualmente ou em grupos. Há regiões divulgadas no Exterior que são ansiosamente procuradas, tais como, o Pantanal ou a Amazônia que, por seus atributos incomuns e surpreendentes, também podem ser incluídas;

- balcão informativo: é extremamente oportuno manter um local destinado ao atendimento da agência de viagens, junto à secretaria do evento, com pessoal 
próprio, bilíngüe ou não, para providenciar reservas de última hora, sugestões turísticas e comercialização de excursões opcionais;

- marcação de bilhetes: em geral, a companhia aérea credenciada providencia o pessoal habilitado encarregado da confirmação ou das alterações de seus próprios vôos, ficando a cargo da agência de viagens as demais modificações;

- câmbio: as agências de viagens, licenciadas para a operação de câmbio, poderão manter postos de atendimento para a troca de moedas, completando, assim, a prestação de serviços. Esses postos serão instalados no Centro de Convenções e/ou no hotel-sede, para maior conveniência das autoridades, convidados especiais, membros da diretoria e participantes;

- assistência médica e seguro de bagagem: em virtude dos elevados custos de atendimento médico-hospitalar de emergência, a inclusão de serviços especializados, tanto no pacote turístico como na taxa de inscrição ao evento, proporciona ao participante garantia complementar de indiscutivel valor promocional, dando destaque ao evento e tranqüilidade à entidade promotora, evitando-se assim possíveis dissabores. As taxas cobradas variam conforme 0 número de participantes e de dias de viagem, qualquer que seja o destino.

\section{Hospedagem}

Em virtude do contato regular e sistemático que as agências de viagens mantêm com os hotéis de várias categorias, para a organização de eventos, essas agências adquirem inegável poder de negociação, buscando tarifas acessiveis, compativeis com o perfil econômico do evento.

Por ocasião da seleção de hotéis, éindispensável uma visita minuciosa para avaliar a localização, estado de conservação, qualidade e conforto das unidades habitacionais e demais serviços que serão usufruidos pelo participante.

É do conhecimento geral, que o padrão de conforto dos hotéis está ligado à sua classificação. Ainda, entre os critérios de seleção, o econômico é representativo, devendo estar direcionado aos interesses do congressista - conforto ou economia (ambos, se possível). O próprio participante não poderá se sentir desservido, pois já sabe que receberá o tratamento compativel com a categoria optada. Após a aplicação dessa sistemática, com os hotéis já reservados, a agência de viagens está em condições de produzir a ficha de reserva, com os detalhes necessários, ou seja, nome, categoria, tarifa, tipo de acomodação, taxa de serviço, café da manhã, sinal para a reserva e outras particularidades variáveis de acordo com o evento e o hotel.

O contato com os participantes será realizado através de assidua correspondência, em perfeita sintonia com a secretaria do evento que fornecerá nomes e endereços, colocando-os a par da disponibilidade de camas nos hotéis, tarifas especiais, mecanismo de reserva e prazos para o pagamento e cancelamentos.
Por via de regra, é solicitada a remessa do valor da primeira diária ou sinal de maior importância como garantia da reserva que será lançado na conta do participante, para acerto final por ocasião da saida (check out).

Seguir-se-á a composição do rooming list e o encaminhamento dos convencionais aos respectivos hotéis escolhidos, respeitando-se as afinidades existentes.

O próximo passo será o de enviar, ao congressista já inscrito, o voucher, cupom ou fax, representando a ordem de serviço e identificando as condições anteriormente estabelecidas. Não se incluem, regularmente, extras em geral e despesas de caráter pessoal, tais como, refeições, bebidas, lavanderia, ligações interurbanas, telex, fax e outras.

Traçado o formato do evento, a agência de viagens poderá contratar a mãode-obra qualificada, destinada ao andamento das atividades para as quais foi contratada, incluindo também a remuneração regulamentar.

\section{Transporte Aéreo}

A companhia aérea selecionada como transportadora oficial deverá ter experiência no setor, freqüência de vôos em horários adequados, tarifas promocionais e, logicamente, maior número de pontos de embarques nacionais ou internacionais, dependendo do evento. É atribuição da agência de viagens, mediante ação cooperada, assegurar grande parte da movimentação dos participantes através da mesma; remeter as ordens de passagens dos convidados especiais; e também, participar da elaboração do pacote turístico, incluindo passagem aérea, hospedagem, recepção e traslado, na tentativa de reduzir os custos aos participantes.

Eventuais gratuidades serão colocadas à disposição da entidade promotora, para definição de seu destino.

\section{Transporte de Superficie}

Dentre as medidas de efeito imediato, a recepção e o traslado representam papel de destaque nos procedimentos iniciais do evento, utilizando a frota de veículos anteriormente selecionada, com destino aos hotéis previstos.

Também merece atenção especial, o planejamento do transporte dos hotéis ao local de realização do evento. A regularidade e intensidade de fluxo irão depender do número de participantes e dos hotéis incluídos no itinerário, bem como das condições de tráfego. Deverá ser estabelecido um cronograma detalhado para que os horários de partidas obedeçam a um esquema exeqüível, em face das circunstâncias assinaladas. Recomenda-se, ainda, divulgar os horários em quadros colocados no saguão do hotel e na secretaria do evento. Da mesma maneira, o transporte para as atividades sociais e turisticas, partindo dos hotéis ou do próprio centro de convenções, deverá ter ação controlada e divulgada. É necessário que haja espaço disponivel para o estacionamento dos veículos destinados ao transporte dos convencionais. A presença de um coordenador de tráfego não deixa de ser um fator 
adicional vantajoso, favorecendo o desempenho de melhor trabalho para o transportador de superficie.

\section{Comunicação em Geral}

A divulgação do evento, assim como as suas atividades turísticas, deverá ser efetuada empregando-se os recursos disponíveis e mais ajustados à sua estratégia mercadológica. Paralelamente ao trabalho de divulgação, a montagem de folheteria elucidativa, com riqueza de detalhes, coloridos e bem-impressos, tanto em português como em inglês ou espanhol, destinada aos eventos internacionais, colocando em destaque os recursos locais, desperta o desejo imediato de participação. A montagem de mala direta objetiva, a ser enviada aos interessados, mediante listagem fornecida pela entidade promotora, indicandoa realização do eventoe suas características principais, representa forte apelo promocional.

Quando o evento tem grande abrangência, a divulgação poderá ser inserida nos meios de comunicação de massa. Tratando-se de grupos especializados, a comunicação será realizada através dos informativos da própria categoria profissional promotora. E como conseqüência, a geração de contatos pessoais ou via telemarketing, incrementando a conquista de novos participantes.

Concluindo, pode-se afirmar que enganam-se aqueles que prematuramente julgam não haver necessidade do envolvimento da agência de viagens, pois seu desempenho é bem definido. Representa o profissional de custo não elevado, remunerado apenas através das comissões provenientes de sua intermediação junto aos fomecedores diversos. Profissional que, através de seu relacionamento sistemático com a hotelaria e os transportes, tem condições de apresentar tarifas adequadas e econômicas, capazes de minimizar custos e aumentar a demanda do evento.

\section{Meios de Hospedagem - Hotéis e Apart-Hotéis}

Fazendo parte do suporte básico do turismo de eventos, a hotelaria vem praticando um marketing bastante agressivo e extremamente moderno. Nos últimos tempos, os hotéis saíram da sua posição estática, aguardando a chegada espontânea do cliente, para uma nova fase, dinâmica, em que vão buscá-lo em seu próprio local de origem.

A hotelaria passou a encarar o turismo de eventos como forma adicional de manter a sua ocupação em níveis mais elevados, não desprezando, entretanto, suas atitudes prioritárias e métodos tradicionais de incrementar a hospedagem. Dentre as medidas de efeito imediato, o evento passou a ser encarado como fenômeno multiplicador de negócios e determinados hotéis tornaram-se verdadeiros especialistas no assunto, adquirindo um know-how surpreendente.

Sabe-se também que o turismo tradicional é fundamentalmente sazonal, tendo maior expressão nos meses de férias e feriados prolongados. Por isso, é extremamente importante que não haja superposição de eventos com a alta temporada turística. Na baixa estação, as possibilidades de comercialização em relação a tarifas, prazos de pagamentos e cancelamentos são mais acessíveis. Como conseqüência lógica, o evento passa a ser disputado pela hotelaria, contribuindo para que os indices de ocupação subam substancialmente.

Em geral, os grandes eventos, acima de 500 participantes, devem ser realizados nos centros de convenções; todavia, existem alguns hotéis, mas poucos, que poderão abrigar tal número elevado de congressistas, utilizando ao mesmo tempo os serviços de hospedagem. Entretanto, quando o evento é de grande porte ou megaevento, acima de 2 mil participantes, deverá ser realizado exclusivamente em centros de convenções.

Comumente, os seminários, convenções, simpósios, conferências e outros, de porte menor, são indicados para serem realizados, com freqüência, em hotéis ou apart-hotéis, devidamente equipados, conjugando por vezes hospedagem e execução do evento, facilitando sobremaneira seu desenrolar.

As empresas comerciais vêm dando preferência aos hotéis e apart-hotéis, para a realização de seus pequenos e médios eventos, harmonizando, ao mesmo tempo, benefícios e custos. Como grande parte dos estabelecimentos não estava preparada para atender esse mercado emergente e crescente, tais estabelecimentos foram obrigados a ampliar e equipar as instalações já existentes. Desse modo, alguns hotéis e apart-hotéis construíram seus próprios auditórios, funcionais, confortáveis, de capacidade variável, com infra-estrutura apropriada (ar condicionado e isolamento acústico), permitindo o andamento do pequeno evento, sem grandes transtornos e com sucesso garantido. E sem custos extremamente elevados.

$\mathrm{O}$ índice de ocupação de auditórios da rede hoteleira e de centros de convenções atingiu posições consideradas excelentes pelos padrões mundiais. Não é somente nas capitais que os eventos têm participação significativa no faturamento dos hotéis/apart-hotéis. No interior e em todo o país, os eventos profissionais e seminários de treinamento já representam quase $70 \%$ da receita de estabelecimentos que trabalham com esse tipo de mercado.

De forma prática, pode-se considerar os hotéis utilizados exclusivamente como meios de hospedagem e aqueles que também têm condições de receber 0 evento. Dependendo da categoria dos hotéis selecionados, os recursos mínimos disponiveis são:

- quartos: ar condicionado, discagem direta, rádio - televisão, geladeira - minibar, cofres individuais, material de toalete, serviço 24 horas;

- reuniões/eventos: voltagem $110 \mathrm{~V}-220 \mathrm{~V}$, área de registro, tradução simultânea. auditórios flexíveis ou fixos com ar condicionado, xerox, serviço de secretaria, vídeo, quadro-negro, microfone, pódio, arcondicionado, local para coffee-break;

- hotel: lanchonete, restaurante, ar condicionado, piscina, sauna - massagem, bar, 
lavanderia, salão de beleza, estacionamento, lojas, área para esportes, área para não fumantes, locação de veículos, transporte próprio, área para agência de viagens, área para câmbio.

Dependendo do perfil do evento, devem ser selecionados hotéis de cinco, quatro e três estrelas e grande número de apart-hotéis, com quantidade de quartos condizentecom suatradição eperiodicidade. Quandooeventose realiza pela primeira vez, o conhecimento do patrocinador é vital, indicando a demanda provável e o interesse que o mesmo poderá despertar no meio profissional correspondente.

\section{Reservas e Tarifas Hoteleiras}

Na seleção dos hotéis, será reservado um número de camas compatível com a necessidade do evento, em apartamentos individuais, duplos ou triplos. Astarifas aplicadas estarão de acordo com a classificação dos hotéis em cinco, quatro e três estrelas ou luxo, primeira e turística. Em cada categoria serão utilizados tantos hotéis quanto necessários. A escolha nesse caso será feita pelo próprio nome do hotel e sua categoria.

Por outro lado, quando o evento é de grande porte as tarifas podem estar agrupadas pela sua natureza, em luxo, primeira e turística, ou seja, como exemplo, os hotéis de luxo terão a mesma tarifa. O participante seleciona apenas o grupo que pretende utilizar, sem indicação do nome do hotel, cabendo à agência de viagens acomodá-lo naqueles onde há disponibilidade de quartos, obedecendo a ordem de inscrição, respeitando sua preferência de tarifa e de categoria.

Feita a reserva das camas necessárias, será oportuno a assinatura de simples compromisso entre as partes, como medida de garantia da prestação de serviços, contemplando os seguintes aspectos:

- nome do evento;

- data da entrada e saida;

- número de apartamentos e noites utilizadas;

- número de gratuidades concedidas;

- prazo para pagamento de sinal;

- prazo para entrega do rooming list;

- prazo para cancelamento sem ônus e modificações necessárias;

- valor das tarifas de grupos (netas e comissionáveis), em reais ou dólares, bem como o período de validade;
- inclusão da taxa de serviço e café da manhã;

A segurança em utilizar um hotel classificado reside no conhecimento dos niveis de conforto, serviços gerais e tarifas aplicadas. Assim, tanto poderá ser aceita a classificação por estrelas (cinco, quatro, três) quanto por categoria (luxo, primeira e turística)

Dependendo da época do ano (alta e baixa estação), as reservas deverão ser efetuadas com a necessária antecipação, evitando-se os inconvenientes decorrentes da falta de acomodação. As reservas poderão ser inicialmente processadas por telefone, diretamente com o Departamento de Grupos do hotel e seguidas de telegrama, carta, telex ou fax confirmatórios. A garantia será maior na medida em que houver um documento hábil que não dê margem a interpretações duvidosas.

Ao ser reservado um número determinado de quartos, o hotel estabelecera a proporção de gratuidades decorrentes, que seráutilizada pela comissão organizadora para acomodar seus convidados especiais e conferencistas.

No geral, o pagamento da primeira diária sela o acordo comercial estabelecido; o restante do valor deverá ser pago diretamente pelo usuário ao sair ou pela própria agência de viagens.

Há hotéis que para aumentar sua ocupação e conforto recorrem a vários serviços adicionais, tais como: restaurantes onde são servidos pratos internacionais ou típicos, bufê à beira da piscina, boate com show ou piano-bar, organização de happyhours, segurançainterna e externa e outros mais, dependendo da criatividade do hoteleiro.

Em relação às tarifas, acredita-se que os custos deverão ser fixados em reais para os eventos nacionais, enquanto para os internacionais somente as tarifas em dólares poderão estabelecer termo de comparação com as demais moedas estrangeiras.

Nos hotéis considerados como sede, que tenham pelo menos 100 apartamentos ocupados por convencionais, há necessidade de previsão de espaço para reuniões da comissão organizadora e montagem de hospitality desk, para informações de caráter geral, controle dos ônibus, orientação turística e, também, de local reservado para a instalação de um posto de câmbio, quando o evento for internacional, comportando semelhante medida. As suites disponíveis poderão ser utilizadas para a acomodação dos convidados especiais ou para reuniões privadas de confraternização, promovidas por empresas comerciais, envolvidas no patrocínio do evento (suites de hospitalidade).

E, por último, recomenda-se a inclusão, no programa oficial, de mapa contendo a localização dos principais hotéis, parafacilitar a escolha do convencional

Embora não seja usual, julga-se que poderá haver maior participação do hotel como um todo durante o evento, como, por exemplo, a cessão sem ônus da ocupação de áreas onde são nornnalmente cobradas taxas de ingresso ou serviço. Essa atitude tornase extremamente simpática, pois o participante é sobretudo seu hóspede. Outrossim, é notório que um cliente satisfeito sempre retornará ao hotel, por razões várias. 
É necessário recomendar que, por ocasião da negociação entre patrocinador e hotel, seja considerada seriamente a provável intervenção da agência de viagens, preservando-se sua intermediação, para que seu trabalho não seja economicamente inviável.

\section{Transportadora Aérea Credenciada}

Nenhum evento tem condições de ser bem-sucedido se uma companhia aérea não for designada como transportadora oficial. Quer o evento seja nacional, quer seja internacional, caberá à companhia aérea imprescindível papel, cuidando principalmente do transporte dos participantes e convidados especiais.

O envolvimento da transportadora oficial iniciar-se-á na fase da captação do evento, quando somará esforços com a entidade patrocinadora e demais segmentos do "trade", no sentido de concretizar sua realização em determinada cidade, estado ou país. Por outro lado, ao concordar em ser a transportadora credenciada, esta conceberá o plano preliminar de trabalho junto aos demais membros da categoria.

É necessário destacar que as companhias aéreas, principalmente as chamadas de "bandeira", por representarem a nação de origem, têm condições maiores de desenvolver um bom trabalho de captação, divulgação e promoção de eventos, em virtude de possuírem grande número de escritórios ou lojas no país e no Exterior, facilitando, destarte, a movimentação dos participantes. Convém enfatizar a interação perfeita das companhias aéreas nas fases correspondentes ao pré, durante e pós-evento, ensejando ações cooperadas nas seguintes formas:

- apoio total: mediante colaboração estreita, recorrendo aos seus representantes, tanto nacionais quanto internacionais

- planejamento e realização: acionando sua estrutura técnica, desenvolvendo atividades conjuntas com a comissão organizadora e a agência de viagens, pertinentes ao empreendimento estabelecido (pretendido);

- colaboração material: abastecimento em número suficiente de shell letters ou shell folders, destinados à correspondência regular, montagem de follheteria elucidativa e peças promocionais para a mala direta, transporte do material promocional, por vezes, representando carga considerável;

- divulgação e promoção: valendo-se de seus delegados ou prepostos, exercendo papel capital no contato e orientação do participante quanto à aquisição das melhores tarifas e vôos, visando sempre a economia e o conforto do mesmo;

- captação geral: juntando-se ao “trade”, em participação de viagens de promoção e de reuniões internacionais (ICCA, ASAE, IT \& ME etc.) para atrair a vinda de eventos internacionais a serem sediados no país, a curto, médio e longo prazo

- atividades turisticas: garantindo assentos em vôos regulares ou especiais, ate mesmo fretamentos, honrando reservas previamenteefetuadas, prestando assistência nos aeroportos, facilitando o embarque e o desembarque dos convencionais;

- passagens aéreas: enviando-as, sob forma de ordem de passagem, para convidados especiais, conferencistas, componentes da diretoria internacional e alguns participantes, por especial deferência;

- confirmação e modificação de vôos: deslocando funcionários, bilíngüe ou não, ao local do evento, para oferecer atendimento personalizado e providenciar as alterações de vôos indispensáveis ao retorno de origem. É conveniente lembrar que um evento tem curta duração e os procedimentos de reserva e alterações de vôos têm que ser realizados com rapidez, dinamismo e eficiência;

- montagem de pacotesturísticos: participandoem pacotes turísticos armados pela agência de viagens, incluindo passagem aérea, hospedagem e traslado, destinados ao Exterior (emissivo) ou para o local-sede do evento no país (receptivo);

- levantamento e coleta de informações: seja de âmbito nacional ou internacional, constituindo forte mecanismo de criação de produtos e promissores negócios;

- publicação e distribuição do calendário de eventos: em livrete, ao menos anualmente, contendo os eventos agrupados por mês, ano, cidade, país ou, ainda, por assunto técnico e fartamente divulgados;

- visitas e contatos: pesquisando entidades de classes que tradicionalmente realizam eventos (congressos, feiras, exposições, semináriosetc.), promovendo seus serviços gerais e oferecendo facilidades condizentes com a versatilidade do mercado;

- assessoria profissional direta: através de contatos regulares desenvolvidos pelos experts elm eventos, sugerindo, quando necessário, posturas apropriadas ao público-alvo

- orientação global: mediante profissionais do Departamento de Grupos e Eventos, prestando completa orientação aos interessados, em todas as áreas, para incrementar o turismo de eventos, receptivo ou emissivo;

- viagens de familiarização (fam trips ou famtours) - viagens de incentivo - convite a jornalistas: participando, colaborando, promovendo e organizando grupos destinados às categorias acima tituladas, em viagens de familiarização ou de incentivo, convidando jornalistas e profissionais do Exterior para conhecerem o 
Pais, revelando seus recursos turísticos e infra-estrutura, para conhecimento, avaliação e divulgação de toda a potencialidade disponível;

- participação nos Convention Bureaus: acompanhando suas atividades, participando da constituição dos mesmos, somando esforços na captação de eventos.

No tocante à qualificação profissional, a grande verdade é que os participantes esperam da companhia aérea credenciada uma qualidade de serviços excepcional, representada por pontualidade, freqüência e boas conexões de vôo, assentos confortáveis e serviço de bordo exemplar, processamento rápido do check in, incluindo despacho de bagagem para o destino final, compatibilizando, assim, custos e beneficios.

Por outro lado, há a expectativa generalizada pela segurança, tanto em terra como a bordo, em razão dos freqüentes seqüestros, bombase atos de terrorismo, bem como o extravio e roubo de bagagem. Há uma série de propostas visando a reversão dessa situação, criando um clima de tranqüilidade, em virtude das medidas que vêm sendo implantadas, ou seja, maior fiscalização e desconfiança generalizada.

Portanto, pelo exposto, pode-se verificar que a companhia aérea exerce indiscutivel papel junto a todos os segmentos turísticos, mesmo porque é, quase sempre, a primeira a ser procurada pela entidade promotora, quando se pensa na realização de um evento.

\section{Bibliografia}

ALMEIDA, E. L. Congressos, convenções, jẹiras, exposições. Organização de eventos. Principios de planejamento e organização. Eventus, 1976.

FARO, M. M. Criatividade: primeiro passo para o sucesso de uma agência de viagens. Høtelnews, agosto, 1978 Turismo de eventos. Hotelnews, janeiro, 1970.

A importância do agente de viagens na indústria do turismo. Injormativo $A B A V$, n. 18, 1989.

O evento como fator de desenvolvimento do Turismo. Eventos Internacional, n. 1, 1975.

. Capacitaçāo para eventos. Marco Zero, n. 20, 1994. 